\title{
Speciation and Determination of Ionic and Trace-Level Colloidal Silver in Selected Personal Care Products by Thermal Lens Spectrometry
}

Korte $D^{1}$, Grahovac $A^{1}$, Jerkič $A^{1}$, Vajdle $O^{2}$, Anojčić $\mathrm{J}^{2}$, Guzsvány $\mathrm{V}^{2}$, Budič $\mathrm{B}^{3}$ and Franko $\mathrm{M}^{1}$

${ }^{1}$ Laboratory for Environmental and Life Science, University of Nova Gorica, Vipavska 13, 5000 Nova Gorica, Slovenia

${ }^{2}$ Department of Chemistry, Biochemistry and Environmental Protection, Faculty of Sciences, University of Novi Sad, Trg Dositeja Obradovića 3, 21000 Novi Sad, Serbia

${ }^{3}$ National Institute of Chemistry, Hajdrihova 19, 1000 Ljubljana, Slovenia

\begin{abstract}
The collinear dual beam thermal lens spectrometric (TLS) detection in batch mode (BM), as well as combined with the flow injection analysis (FIA), was applied to determine the colloidal silver in personal care products available

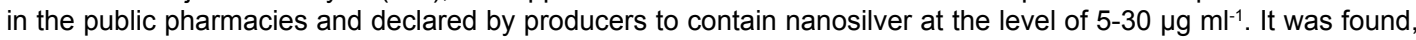
that the examined samples contain mainly ionic silver ( $99 \%$ or more), whereas the colloidal form of silver is at the level of less than $1 \mathrm{\mu g} \mathrm{ml}^{-1}$. The TLS methods were confirmed to be fast, precise, highly accurate and highly sensitive with limits of quantitation of $0.30 \mathrm{ng} \mathrm{ml}^{-1}$ and $1.50 \mathrm{ng} \mathrm{ml}^{-1}$ and relative standard deviations not higher than $1.2 \%$ and $6.0 \%$ for BM- and FIA-TLS configuration, respectively. The developed TLS methods have nearly 60 times lower $L O Q$ values concerning the colloidal silver determination than the classical spectrophotometric method. To verify the obtained results of the real sample analysis the total amount of ionic silver was determined by the use of ICP-OES technique.
\end{abstract}

Keywords: Silver nanoparticles; Colloidal silver; Personal care products; Thermal lens spectrometric determination; Flow injection analysis

\section{Introduction}

Inorganic nanoparticles exhibit physical, chemical and biological properties which attract much interest in a broad spectrum of applications including the field of pharmaceutics and personal care products. Inorganic nanoparticles present a great potential for achieving good antibacterial and antimicrobial activity [1]. Among inorganic antibacterial agents, colloidal silver has been known and employed already by the ancient civilizations and intensively employed to fight infections and control spoilage [2,3]. The main advantage of using colloidal silver is the fact, that microbes are not capable of developing resistance against silver nanoparticles, as they do against conventional antibiotics by developing mutations, since the nanoparticles attack several different targets in microorganisms at once. The antibacterial property of the silver nanoparticles (AgNPs) probably can be related to the release of silver ions from AgNPs, with the evidence of the size dependent in vitro AgNP toxicity, which can be explained by generation of reactive oxygen species, loss of mitochondrial activity or DNA damage [4-7].

Nowadays the increased antibiotic resistance of disease-causing microbes has lead to the renewed interest in silver and its compounds as biocidal agents. They serve as antibacterial components in dental resin composites [8,9], in coatings of medical devices [10-12], surgical prostheses [13], wound dressings [14,15], and in novel advanced biocomposite materials for medical use [16]. Actually, over 430 consumer products are currently reported to be on the market worldwide [17] with the expectable increase of their number in the forthcoming years. Silver nanoparticles are incorporated in some products such as the deodorizing shoe inserts, sports socks, soaps, lotions, nasal sprays and also in household appliances such as washing machines, air conditioners and other technical products.

However, some possible risks associated with the usage of silver containing products were reported such as argyria $[18,19]$, which is a condition characterized by a blue-gray discoloration of the skin and is related to excessive intake of silver. The concerns about the possible toxicity of colloidal silver to aquatic organisms and humans have led to recently issued regulations by the FDA regarding the application of silver. The FDA ruled that over the counter products containing colloidal silver (suspended silver nanoparticles) or silver salts are not generally recognized as safe for human use [20]. Having in mind the issues discussed above, as well as the need for quality control and quality assurance in production of products containing colloidal silver, there is an increasing need for the development of reliable, simple and easy to use analytical methods for the determination of colloidal silver in different products available on the market.

In general, a wide spectrum of measurement techniques such as atomic absorption spectrometry [21], inductively coupled plasma atomic emission spectrometry [22], voltammetry [23], potentiometry [24,25], optical sensors [25,26], and spectrophotometry [27] can be utilized for the determination of silver. Additionally, kinetic methods have been developed, where the silver ion serves as catalyst and is determined based on the rate of catalyzed reactions [28,29]. In the above mentioned cases specific sample pretreatment procedures are often required, including digestion and/or preconcentration step(s). In some cases the disadvantages of the methods include reagents/ ionofores which are not always available on the market, while in some cases the reaction conditions are associated with specific and complicated experimental requirements.

Recently, there is an increasing number of analytical methods devoted to the detection, as well as to determination of the number

*Corresponding author: Dorota Korte, Laboratory for Environmental and Life Science, University of Nova Gorica, Vipavska 13, 5000 Nova Gorica, Slovenia, Tel: +38653315238; E-mail: Dorota.Korte@ung.si

Received January 16, 2018; Accepted January 25, 2018; Published January 31, 2018

Citation: Korte D, Grahovac A, Jerkič A, Vajdle O, Anojčić J, et al. (2018) Speciation and Determination of Ionic and Trace-Level Colloidal Silver in Selected Personal Care Products by Thermal Lens Spectrometry. Pharm Anal Acta 9: 573. doi: 10.4172/2153-2435.1000573

Copyright: ( 2018 Korte D, et al. This is an open-access article distributed under the terms of the Creative Commons Attribution License, which permits unrestricted use, distribution, and reproduction in any medium, provided the original author and source are credited. 
size distribution of colloidal silver particles. A powerful asymmetric flow field-flow fractionation-inductively coupled plasma mass spectrometric method was elaborated for the analysis of silver nanoparticles in antimicrobial customer products including the derivation of number size distributions the 1-100 $\mathrm{nm}$ range in a single measurement. The outputs of the method were confirmed by the centrifugal liquid sedimentation, dynamic light scattering and transmission electron microscopy [30]. An analogous measurement technique was elaborated for determination of AgNPs in chicken meet [31]. Beside the highly sophisticated measurement techniques different electroanalytical measurement protocols based on voltammetry [32-34] and potentiometry [35] are recognized as simple techniques suitable for determination of colloidal silver. Furthermore, the relatively simpler optical detection based techniques can as well serve for the determination and speciation of colloidal and dissolved ionic silver in the drinking water treated by $\mathrm{Ag}^{+}$or colloidal silver [36]. The colloidal and ionic silver in water samples was determined by colorimetric solid phase extraction which involves the extraction of $\mathrm{Ag}^{+}$from water by passage through a solid phase membrane impregnated with the reagent (5-[4-(dimethylamino)benzylidene]rhodanine), while quantitation of the formed colored compound was performed by diffuse reflectance spectrometry. The colloidal form of silver was converted into the ionic form by chemical agent oxone, and determined as $\mathrm{Ag}^{+}$. Furthermore, a rapid and easy to use method based on FIA combined with spectrophotometric detection was introduced for determination of colloidal silver and ionic silver after reduction of $\mathrm{Ag}^{+}$ions by $\mathrm{NaBH}_{4}$ to form AgNPs. The absorbance due to the initially present colloidal silver and the generated AgNPs was determined spectrophotometrically [37]. The same approach was later used for the determination of the colloidal and ionic silver by thermal lens spectrometric (TLS) technique in a water sample from drinking water supplies of the International Space Station [38].

The aim of this work was to expand the applicability of the trace level and simple, high sample throughput analytical method based on TLS detection for determination of colloidal, ionic and total silver contents $[37,38]$ to the analysis of personal care products based on colloidal silver. We also aimed to validate the performance of the method in case of other samples rather than drinking water, e.g. personal care products, and the performance of the method as analytical tool for quality control in case of personal care products containing colloidal silver. This was realized by the analysis of five commercially available personal care products.

The selected personal care products, a disinfection water, water for internal intake to improve the general state of organism and nose drops, all available in a public pharmacy and declared by producer to contain nanosilver were examined.

The proposed method is based on TLS detection, in which the examined solution is periodically excited by a modulated laser light beam (pump beam), which generates a temperature gradient and a consequent refractive index gradient (thermal lens) [16,38]. This is because the irradiated sample is heated due to the nonradiative relaxation of absorbed energy. The thermal lens can be detected by a second laser beam (probe beam) [38,39]. The thermal lens changes the light intensity on the axis of the probe beam and these changes are directly related to the absorbance $A$ of the sample (Eq. 2). For the steady state thermal lens (excitation time is much longer than the thermal lens time constant) and sample located at $3^{1 / 2}$ times the confocal distance $Z_{c}$ beyond the probe beam waist, which is theoreticallythe position for achieving the maximum TLS signal, the relative changes of the axial probe beam intensity (the thermal lens signal) resulting from the interaction of the probe beam with the thermal lens, can be describe as [40]:

$$
\Delta I / I=2.303 E A+(2.303 E A)^{2} / 2+\ldots
$$

where the enhancement factor $E$, relative to the transmission mode measurements (such as in spectrophotometry and related transmission mode techniques) is given by:

$$
E=-P(d n / d T) / 1.91 \lambda k
$$

Where $\lambda$ is the probe beam wavelength and $P$ the excitation laser power, while $(d n / d T)$ and $k$ are the temperature coefficient of the refractive index and the thermal conductivity of the medium, respectively. The confocal distance of the probe beam is defined as $Z_{c}=$ $2 \pi a^{2} / \lambda$ where $a$ is the probe beam radius at its waist.

For low-concentrations or weakly absorbing samples $(A<0.1)$ the second, and other higher order terms in Eq. (1) can be neglected. Under such conditions TLS signal is linearly proportional to the absorbance, excitation power and enhancement of the signal due to the thermooptical properties $(d n / d T, k)$ of the sample. This makes the TLS technique a highly sensitive method for the determination of chemical species at very low concentrations [41,42].

To optimize the sample throughput and the sensitivity as well as limits of detection, the experiments were performed in the batch mode (BM) and in the flow injection system (FIA) with a TLS spectrometer used as a detector. Additionally, spectrophotometric measurements were performed for comparison. In the case of the total silver determination the ICP-OES technique served as the comparative determination pathway for validation of TLS results.

\section{Materials}

\section{Reagents and solutions}

The following chemicals were used as purchased, without further purification: $\mathrm{AgNO}_{3}$ (Carlo Erba, min. 99.8\%, Italy), $\mathrm{NaBH}_{4}$ (Carlo Erba, min. 99\%, Italy), $\mathrm{NaOH}$ (Carlo Erba, min. 99.8\%, Italy), $\mathrm{Na}_{2} \mathrm{HPO}_{4}$ (Acros Organics, min. 99\%, Germany), 65\% $\mathrm{HNO}_{3}$ (Baker, VLSI Grade, Germany). All solutions were prepared fresh daily using high purity double-deionized $\mathrm{H}_{2} \mathrm{O}\left(18 \mathrm{M} \Omega \mathrm{cm}^{-1}\right)$ obtained with the Purelab Option-Q system. Solutions containing silver were protected from light by covering them with an aluminum foil.

\section{Working standard solutions}

For constructing the calibration curve, the stock solution of $\mathrm{Ag}^{+}(1$ $\mathrm{mg} \mathrm{ml}^{-1}$ ) was prepared by dissolving $15.7 \mathrm{mg}$ of $\mathrm{AgNO}_{3}$ in $10.0 \mathrm{ml}$ of water. Working solutions with silver ion concentrations in the range of $0.020-1.20 \mu \mathrm{g} \mathrm{ml}^{-1}$ were prepared by dilutions of appropriate volumes of the stock solution in water to $10.0 \mathrm{ml}$ final volume. In the case of the spectrophotometric and TLS measurement techniques the colloidal silver was chemically generated/formed in such solutions.

\section{Formation of silver colloids}

The generation of silver colloids is based on the chemical reduction of silver ions by borohydride and follows the reaction:

$$
2 \mathrm{AgNO}_{3}+2 \mathrm{NaBH}_{4}+6 \mathrm{H}_{2} \mathrm{O} \rightarrow 2 \mathrm{Ag}+7 \mathrm{H}_{2}+2 \mathrm{NaNO}_{3}+2 \mathrm{H}_{3} \mathrm{BO}_{3}
$$

An excess of sodium borohydride is needed $\left(\left[\mathrm{NaBH}_{4}\right] /\left[\mathrm{AgNO}_{3}\right]=\right.$ 2 at least) to reduce the ionic silver to colloidal form and to stabilize the formed silver nanoparticles [39]. 
The $0.6 \mathrm{mM}$ sodium borohydride at $\mathrm{pH} 12.5$ was used as a reductant [37,38]. For this purpose, an aqueous solution of $\mathrm{NaOH}$ was prepared by dissolving $5 \mathrm{~g}$ of $\mathrm{NaOH}$ in $95 \mathrm{ml}$ of water, than $8.2 \mathrm{ml}$ of such solution was mixed with $500 \mathrm{ml}$ of water to obtain aqueous solution of $\mathrm{NaOH}$ with $\mathrm{pH}$ 12.5. To obtain $0.6 \mathrm{mM}$ concentration of the reductant, the stock solution of $0.1 \mathrm{M}$ sodium borohydride at $\mathrm{pH} 12.5$ was prepared by dissolving $0.095 \mathrm{~g}$ of $\mathrm{NaBH}_{4}$ in $25 \mathrm{ml}$ of aqueous solution of $\mathrm{NaOH}$ with $\mathrm{pH} 12.5$ and further diluting $3 \mathrm{ml}$ of obtained solution to $500 \mathrm{ml}$ by $\mathrm{NaOH}$ solution with $\mathrm{pH}$ 12.5. For the analysis, $1 \mathrm{ml}$ of 0.6 $\mathrm{mM} \mathrm{NaBH}_{4}(\mathrm{pH}$ 12.5) was added to each prepared concentration of working standard solutions to fill-in the volume of $10.0 \mathrm{ml}$. In such a way the basic criteria concerning the AgNPs generation, i.e. the initial concentration of sodium borohydride was at least twice in regard to the concentration of silver nitrate, was fulfilled for the entire investigated silver ion concentration range, and corresponding concentrations of $\mathrm{Ag}^{0}$ as $\mathrm{AgNPs}$ were obtained.

\section{Real samples}

Five commercially available personal care product samples were examined by TLS and spectrophotometric measurement techniques concerning their AgNPs contents, while the ICP-OES measurements served the information about the total silver content in the same samples. The target samples were defined by the declaration of producers as follows:

Sample 1: Colloidal silver, $50 \mathrm{ml}$ nasal spray for disinfection of nose and air passages. Ingredients: water, colloidal silver (20 $\left.\mu \mathrm{g} \mathrm{ml}^{-1}\right)$,

Sample 2: Colloidal silver, $50 \mathrm{ml}$ spray for disinfection of wounds. Ingredients: water, colloidal silver $\left(15 \mu \mathrm{g} \mathrm{ml}^{-1}\right)$,

- Sample 3: Colloidal silver, $50 \mathrm{ml}$ nose drops. Ingredients: water, colloidal silver $\left(25-30 \mu \mathrm{g} \mathrm{ml}^{-1}\right)$,

Sample 4: Colloidal silver water, $200 \mathrm{ml}$, for internal intakes as antibacterial agents. Ingredients: water, colloidal silver $(5 \mu \mathrm{g}$ $\left.\mathrm{ml}^{-1}\right)$,

- Sample 5: Colloidal silver water, $200 \mathrm{ml}$, for internal intakes to improve the general state of organism. Ingredients: water, colloidal silver $\left(15 \mu \mathrm{g} \mathrm{ml}^{-1}\right)$.

The determination of the concentration of silver nanoparticles in all above mentioned samples was performed on the basis of the linear part of calibration curves. In the case of spectrophotometric and TLS measurement techniques the concentration of total silver was determined by adding $\mathrm{NaBH}_{4}$ as reductant to each of the samples, after appropriate $\mathrm{pH}$ adjustment, whereas the concentration of the initially present colloidal silver was determined without adding the reductant. In all cases the measurement procedure was repeated three times and the average concentrations and the adequate standard deviations were calculated. The ICP-OES measurement served the experimental data about the total silver content in the samples measured in the $\mathrm{Ag}^{+}$form after appropriate sample pretreatments.

It can be note that in the case of determination of the amount of total silver in the examined samples, if they were such experimental request, they were properly diluted to ensure the measurements within the linear part of the calibration curves.

\section{Samples for determination of silver deposited on containers}

Determination of the amount of silver species deposited on the containers (glass bottles) in which the solutions/suspensions were purchased, was performed by quantitative washing the bottles with 5 $\mathrm{ml}$ of $0.1 \mathrm{M} \mathrm{HNO}_{3}$. The washing solution was prepared by adding 32 $\mu \mathrm{L}$ of $65 \% \mathrm{HNO}_{3}$ to $5 \mathrm{ml}$ of $2 \times \mathrm{DI}$ water. On this way the silver species are chemically converted into ionic silver. In the next step for the adjustment of the $\mathrm{pH}$ before further analysis of the solution obtained by washing of the sample containers, a $5 \mathrm{mM}$ phosphate buffer at $\mathrm{pH} 12.5$ was used. The buffer was prepared by dissolving $70 \mathrm{mg}$ of $\mathrm{Na}_{2} \mathrm{HPO}_{4}$ in $100 \mathrm{ml}$ of water. To adjust the $\mathrm{pH}$ of the buffer solution to 12.5 , the solution of $0.1 \mathrm{M} \mathrm{NaOH}$ was applied. This was prepared by dissolving $0.2 \mathrm{~g} \mathrm{NaOH}$ in $50 \mathrm{ml}$ of water. $54 \mathrm{~mL}$ of $0.1 \mathrm{M} \mathrm{NaOH}$ was then mixed with the buffer to obtain $5 \mathrm{mM}$ phosphate buffer at $\mathrm{pH}$ 12.5. In such solution the $\mathrm{NaBH}_{4}$ reduced the $\mathrm{Ag}^{+}$content into $\mathrm{Ag}$, and the nanoparticles were formed under controlled conditions, which were analyzed by TLS techniques.

\section{Validation of the analytical methods}

Validation of the UV-VIS spectrophotometric, BM-TLS, FIATLS and ICP-OES methods was performed as recommended by the European Union (EUR-FA Guide, Annex I) and by the IUPAC guidelines [43], evaluating the following performance parameters: linearity, limits of detection (LOD) and quantitation (LOQ) by analysing standard solutions of silver in the case of spectrophotometric and TLS methods as AgNPs, and in the case of the ICP-OES as $\mathrm{Ag}^{+}$ species. In all cases the LODs and LOQs were evaluated as LOD $=3 \times$ $\mathrm{SD}_{\mathrm{xy}} / \mathrm{b}$ and $\mathrm{LOQ}=10 \times \mathrm{SD}_{\mathrm{xy}} / \mathrm{b}$ (where $\mathrm{SD}_{\mathrm{xy}}$ is the standard deviation of the response of the blank signal, and $b$ is the slope of the calibration curve) [44].

\section{Statistical analysis}

The results obtained for colloidal silver as well as for total silver content in real samples measured by BM-TLS, FIA-TLS, spectrophotometric and ICP-OES techniques with optimised measurement protocols were considered by their statistical analysis. In all cases the confidence interval was calculated on the basis of $t$-distribution (the standard deviation was estimated from the sample data) and by the use of equation:

$$
\bar{x} \pm t_{\dot{a}} S D / \sqrt{n}
$$

where $\bar{x}$ is the mean value/average amount of the measured target analyte, SD is its standard deviation, $n$ is the sample size and $t_{\alpha}$ is the value determined by $t$-distributon table for $\alpha=0.01$ and $n$ - 1 degrees off freedom [45].

\section{Measurement Techniques and Instrumentation}

\section{Thermal lens spectrometry}

TLS measurements in batch mode: To determine the presence and concentration of colloidal and ionic silver after its chemical conversion into AgNPs, a dual-beam TLS spectrometer in batch configuration mode (BM-TLS, Figure 1) was used in accordance with our earlier published paper [38]. Briefly: The sample was placed in a 10 mm optical path quartz cuvette (HELLMA, model 100-QS). The TLS measurements were performed by utilizing a Krypton laser (Innova 300C, COHERENT) as the excitation beam source. The laser operated at $407-413 \mathrm{~nm}$ multiline emission and provided $115-195 \mathrm{~mW}$ power at the location of the detection cell. The induced thermal lens was probed by a He-Ne laser (UNIPHASE, Model 1103P) of $2 \mathrm{~mW}$ output power at $632.8 \mathrm{~nm}$ and monitored by a photodiode (THORLABS, model PDA 36A-EC) placed behind a pinhole and an interference filter (633 nm, MELLES GRIOT, model FL632.8-1), and connected to a lock- 
Citation: Korte D, Grahovac A, Jerkič A, Vajdle O, Anojčić J, et al. (2018) Speciation and Determination of lonic and Trace-Level Colloidal Silver in Selected Personal Care Products by Thermal Lens Spectrometry. Pharm Anal Acta 9: 573. doi: 10.4172/2153-2435.1000573

in amplifier (STANFORD RESEARCH INSTRUMENTS, model SR830 DSP) and to a PC for data storage and treatment. The pump beam was modulated by a mechanical chopper (SCIENTIC INSTRUMENTS, Control unit model 300C, chopping head model 300CD, chopping disks model $300 \mathrm{H}$ ) at $40 \mathrm{~Hz}$, which provided the maximum signal to noise ratio. Each beam was focused by a $25 \mathrm{~mm}$ diameter lens of 100 $\mathrm{mm}$ focal distance (EDMUND OPTICS) and directed onto the dichroic mirror (HR488+514, HT633 $/ 45^{\circ}$, LASER COMPONENTS) by a set of broad band, flat mirrors (400-750 nm, THORLABS, model BB1-E02). The dichroic mirror enabled overlapping and collinear propagation of the pump and probe beams and directing them onto quartz detection cell, before reaching the detector.

Thermal lens spectrometry with flow-injection mode measurements: In case of the thermal lens spectrometry with flowinjection measurement mode (FIA-TLS) the quartz cuvette was replaced by a flow through sample cell connected to the flow injection unit, which is schematically presented in Figure 2.

The flow injection system consisted of a HPLC pump (SHIMADZU LC10Ai), used to deliver the carrier solution transporting the sample to the $10 \mathrm{~mm}$ pathlength $(8 \mu \mathrm{l})$ flow through detection cell (HELLMA, model 178.173-QS). The sample was injected through the metal free injection valve (RHEODYNE, model 7725) equipped with a $100 \mu \mathrm{l}$ peek sample loop (CHEMINERT, VICI). The carrier was pumped through the system at $0.6 \mathrm{ml} \mathrm{min}{ }^{-1}$ flow rate.

\section{UV-VIS spectrophotometry}

The plasmon resonance absorption spectra of synthesized silver nanoparticles either for the standard solutions/suspension or for the investigated samples were recorded on a dual beam spectrophotometer (PERKIN ELMER, model Lambda 650) in a $10 \mathrm{~mm}$ optical path quartz cuvette (HELLMA, model 100-QS). All the spectra were recorded with

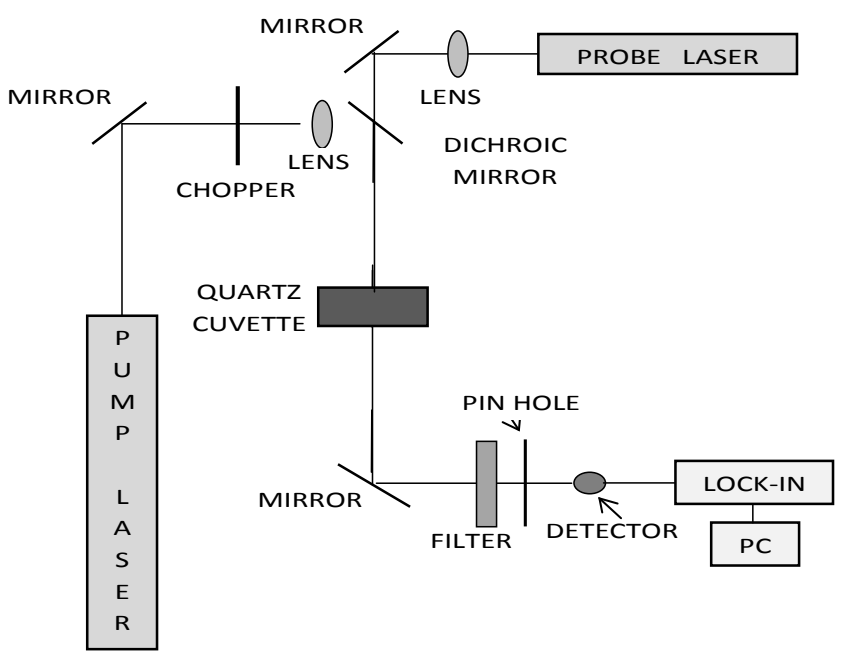

Figure 1: Shematic diagram of the thermal lens spectrometer [38].

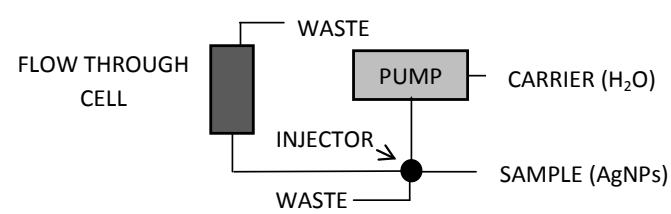

Figure 2: Scheme of the flow injection unit used in the FIA-TLS measurements [38] respect to the double deionized water containing only $\mathrm{NaBH}_{4}$ as a blank.

\section{Inductively coupled plasma optical emission spectrometry}

The verification of the results obtained by UV-VIS spectrophotometry and TLS techniques was performed by the use of inductively coupled plasma optical emission spectrometer (ICPOES) (VARIAN, model 715 ES) which enabled the quantitation of the total ionic silver concentrations in the examined personal care product samples. Prior to their analysis the samples were digested in a microwave oven (MILESTONE, model Ethos 1) using $\mathrm{HNO}_{3}$ and quartz digestion vessels.

\section{Scanning electron microscopy}

Scanning electron micrographs of the synthesized nanoparticles of AgNPs were recorded by a scanning electron microscope (SEM, JSM7100F, JEOL) coupled with energy dispersive X-ray (EDX) detector (XMax-80, Oxford) at primary beam voltage $20.0 \mathrm{kV}$. The micrographs have been acquired both with secondary electron and back-scattered electron detection working modes.

\section{Dynamic light scattering}

The determination of AgNPs sizes for the lowest concentration

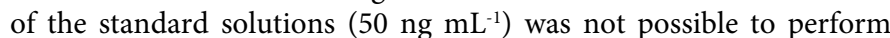
by the use of SEM because of its insufficient resolution. Thus, the characterization of AgNPs in the lowest examined concentration in solution was done by the use of a dynamic light scattering system (DLS, Brook Haven 90 plus/Bi-mas). This instrument enables determination of the AgNPs size in the range between 2-2000 nm under the condition that the nanoparticles do not aggregate.

\section{Results and Discussion}

The thermal lens spectrometry, both in BM and in FIA working configurations, was applied for determination of the content of colloid and total silver in the samples, the later one as the sum of the initially present colloidal silver and the colloidal silver obtained from the same samples from the ionic silver, which was present initially into the samples as well, after its reduction to elementary one. The calibration curve based analytical methods were applied in the case of both TLS measurement configurations for the analysis of the personal care product samples. Comparative measurements were performed by spectrophotometry for the determination of the AgNPs. For the other type of comparison the ICP-OES measurement technique served the information about the total silver content chemically converted into its ionic form prior to the measurements for all considered samples.

\section{Optimization of the analytical methods for model suspensions}

Spectrophotometry: The absorption spectra of the AgNPs at their different concentrations into the investigated suspensions from the synthesis described by the reaction in Eq. 3 are shown in Figure 4.

As it can be seen, the spectra of silver nanoparticles in aqueous solution/suspension exhibit a plasmon resonance peak located in the visible spectral range with maxima close to $400 \mathrm{~nm}$ (Figure 3). Such plasmon resonance effect results from the interaction of the electromagnetic field with silver nanoparticles and consequent oscillation of the electron gas on the surface of the nanoparticles, whereby the electromagnetic radiation is absorbed during this process. This plasmon excitation can decay non-radiatively into electron-hole pairs through intraband or interband excitations and also radiatively by 
Citation: Korte D, Grahovac A, Jerkič A, Vajdle O, Anojčić J, et al. (2018) Speciation and Determination of lonic and Trace-Level Colloidal Silver in Selected Personal Care Products by Thermal Lens Spectrometry. Pharm Anal Acta 9: 573. doi: 10.4172/2153-2435.1000573

Page 5 of 10

photon emission [33-36]. In addition, the wavelength of the plasmon absorption maximum in a given solvent/media can be used to indicate the particle size.

In the present case the recorded spectrums, scanning electron micrographs (Figure 4) and DLS measurements confirmed that the increase in AgNPs concentration increases also the range of sizes of the nanoparticles formed, the maximum of the number size distribution, as well as the wavelength of absorption maximum.

From the Figure 3 from the spectrums it can be recognized that the absorption peak of silver nanoparticles increases in height and width with increasing the silver nanoparticle concentration. According to the comparison of the observed absorption band and its maximum close to $400 \mathrm{~nm}$ with the literature data the method applied for synthesis of AgNPs in this work yields particles with average size between 4 and $40 \mathrm{~nm}$ in the investigated target analyte concentration range. This corresponds well additionally with the observed maximum from other literature sources [21-25]. Furthermore, the same fact was confirmed by SEM measurements (Figure 4) concerning the investigation of the AgNPs sizes for different concentration of the set of standard solutions/ suspensions after their appropriate sample pretreatment.

In all investigated cases the size of AgNPs was found by measuring the diameter of all particles seen on micrographs recorded for different position on the samples and the average size and its standard deviation were calculated from there. The size of AgNPs observed by SEM and obtained from the dried standard suspensions/solutions with different defined initial concentrations, depends on their concentration in the initial suspensions (Figure 5). The main trend concerning the nanoparticles size is that with the increase of AgNPs concentration in the investigated suspensions, the average AgNPs size changes from 4 to $39 \mathrm{~nm}$. For higher concentrations as $5 \mu \mathrm{g} \mathrm{mL}^{-1}$ and above the average

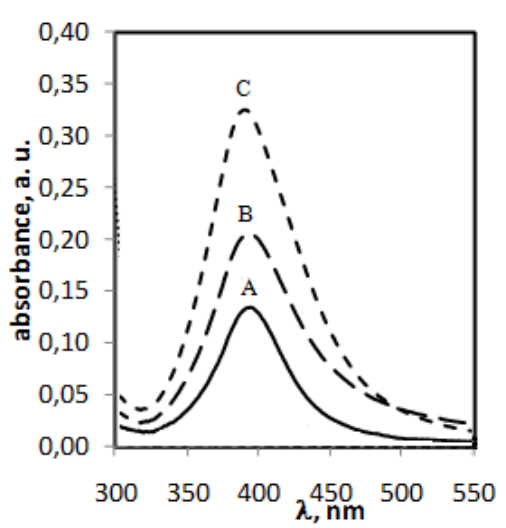

Figure 3: UV-VIS spectra of silver colloids corresponding to AgNPs concentrations 1 (A), 2 (B), $3 \mathrm{\mu g} \mathrm{ml}^{-1}(\mathrm{C})$. size of the nanoparticles does not change significantly, although the number of different sizes of AgNPs increases, what was reflected in higher values of standard deviations illustrated in some cases by error bars on the appropriate columns of the histogram (Figure 5). As the numerical values of the standard deviations: that is lower than 0.5 $\mathrm{nm}$ for $0.05 \mu \mathrm{g} \mathrm{ml}^{-1}$ and $1 \mu \mathrm{g} \mathrm{ml}^{-1}$ of AgNPs solution/suspension, and significantly higher as $6 \mathrm{~nm}$ and $8 \mathrm{~nm}$ for $5 \mu \mathrm{g} \mathrm{ml}^{-1}$ and $15 \mu \mathrm{g} \mathrm{ml}^{-1}$, respectively.

It is important to note that since it was not possible to determine the size of AgNPs in the examined solution/suspension of $0.05 \mu \mathrm{g} \mathrm{ml}^{-1}$ by SEM, because of insufficient resolution of the instrument, it was performed by the use of DLS measurement technique as described in the experimental part (for details see in Section 3). The required condition of applying DLS instrument for particles characterization is the not occurrence of the particles aggregation process. Thus, this measurement technique was convenient for the investigation of the suspensions of the AgNPs in concentration range below $1 \mu \mathrm{g} \mathrm{ml}^{-1}$.

Additionally, from the set of absorption spectra recorded for the broader AgNPs concentration range it was recognized that the absorbance maximum shifts from $400 \mathrm{~nm}$ to $425 \mathrm{~nm}$ in the case of the concentrations of AgNPs $>5 \mu \mathrm{g} \mathrm{ml}^{-1}$. This causes significant and from analytical viewpoint unfavored changes in the maximum of absorbance, which is more than $10 \%$, giving on such way a concentration framework for the application of the spectrophotometric method. Calibration curve for determination of the initial concentration of AgNPs or $\mathrm{Ag}^{+}$chemically converted into AgNPs prior to measurements was constructed by measuring the absorbance at $400 \mathrm{~nm}$ for different concentrations of standard AgNPs solutions/suspensions in the initial concentration range of $\mathrm{Ag}^{+}$chemically converted into the AgNPs and expressed as $0.090-1.2 \mu \mathrm{g} \mathrm{ml}^{-1}$ and the obtained equation of the regression line i.e. calibration curve was defined as follows: $y=0.074 x$ $+0.159\left(R^{2}=0.996\right)$. In this model sistem the RSDs of the obtained absorbances were in the range of $1.2-3.8 \%$.

As for the analytical outlines of the spectrophotometric measurements they are in agreement with our earlier published paper [37], in which under the optimized experimental condition the absorbance of AgNPs shows linear dependence on their concentration in the range of $0.15-5.00 \mu \mathrm{g} \mathrm{ml}^{-1}\left(R^{2}=0.998\right)$. It is important to note, that in earlier experiments the reaction time was much shorter than in our present case, which resulted in the shift of that calibration curve to higher concentration range. Furthermore, the earlier achieved LOD was $50 \mathrm{ng} \mathrm{ml}^{-1}$, which is nearly twice higher than in the present case.

The thermal lens spectrometry: For TLS calibration curve in batch mode for the model systems, the value of the lock-in signal is plotted as a function of the concentration of AgNPs standard solutions/suspensions. The obtained relationship is not linear in wider investigated concentration range of the target analyte from $0.30 \mathrm{ng} \mathrm{ml}^{-1}$
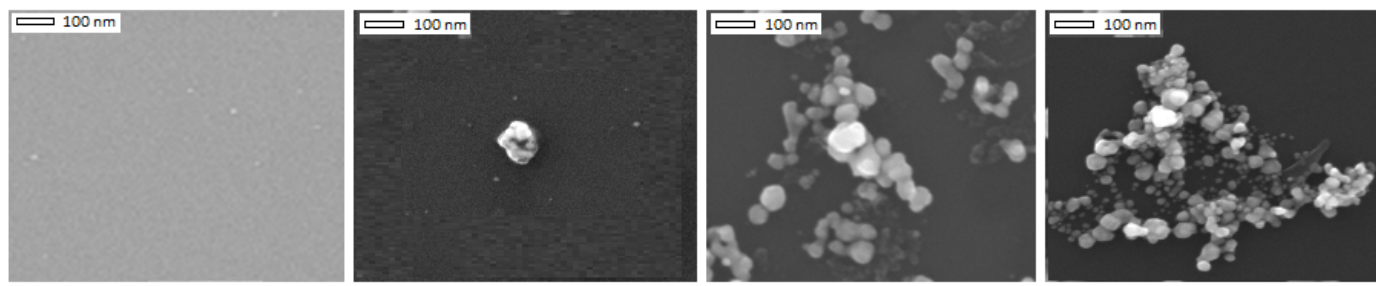

Figure 4: Scanning electron micrographs of the synthesed AgNPs recorded for the following initial concentrations: a) $50 \mathrm{ng} \mathrm{ml}^{-1}$, b) $1 \mu \mathrm{g} \mathrm{ml} \mathrm{l}^{-1}$, c) $5 \mu \mathrm{g} \mathrm{ml} \mathrm{l}^{-1}$ and d) $15 \mu \mathrm{g} \mathrm{ml}^{-1}$ 


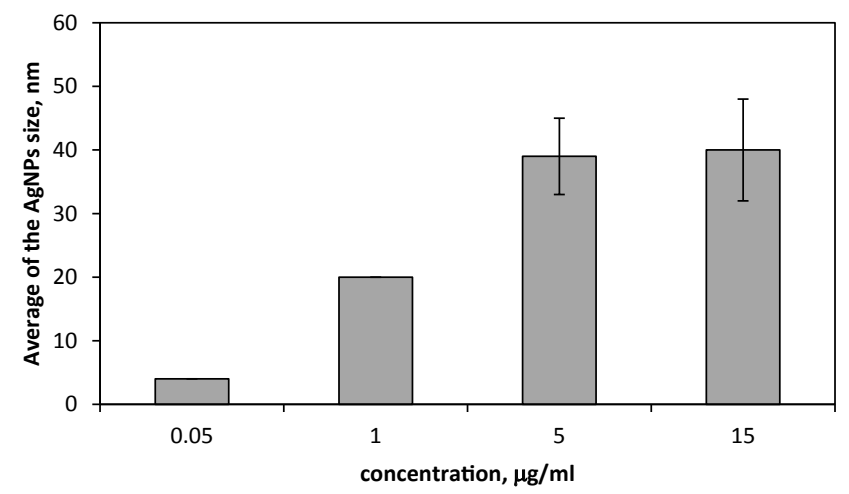

Figure 5: Dependence of AgNPs size on the concentration in the solution. For the first two AgNPs concentration the error bars are too small to be noticed on the graph.

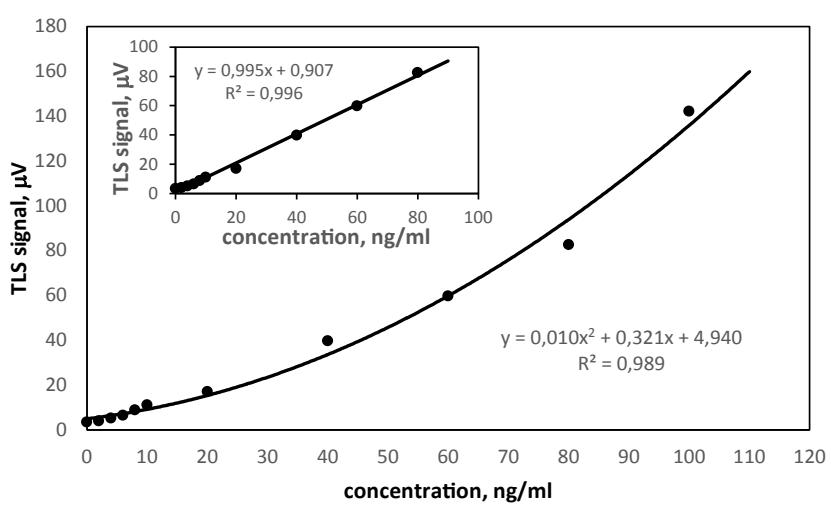

Figure 6: The TLS signal dependence on the concentration of AgNPs in batch mode measurements in the wider concentration range of the target analyte between 0.30 and $100.0 \mathrm{ng} \mathrm{ml}^{-1}$. The inset ilustrates the calibration curve of the analytical method.

to $100 \mathrm{ng} \mathrm{ml}^{-1}$ (Figure 6), but this phenomena probably does not results from the nonlinearities describe by Eq. 2 since the absorbance is very low $(\mathrm{A}<0.1)$ for the analyzed target analyte concentration range. The nonlinearity in the present TLS calibration curve for concentrations of AgNPs $>80 \mathrm{ng} \mathrm{ml}^{-1}$ originates rather from the changes in the magnitude of absorbance maximum for the concentrations higher than $80 \mathrm{ng} \mathrm{ml}^{-1}$ caused by the change in the range of AgNPs sizes. It was mentioned above, that with the increase of AgNPs concentration, the width and height of plasmon resonance peak increases, what increases the total absorbance for the multiline excitation $(407-423 \mathrm{~nm})$. So, the calibration curve shows good linearity $\left(y=0.995 x+0.907 ; R^{2}=0.996\right)$ only for AgNPs concentrations from $0.30-80 \mathrm{ng} \mathrm{ml}^{-1}$ the insert in Figure 6 .

The signals from the measurements of the standard solutions performed in triplicate showed RSD values from 0.3 to $1.2 \%$ for higher and lower AgNPs concentrations, respectively.

To enable easier handling of the investigated suspensions and to increase the number of measurements the FIA working mode, in which the examined standard AgNPs suspensions were injected into the carrier water phase in triplicates, was applied for the analysis of the same suspensions which were investigated in BM-TLS working regime. The experiment outlines are illustrated by Figure 7.

For the development of the FIA-TLS analytical method the lock in signal peak maxima were correlated with the appropriate injected AgNPs concentrations. The obtained equation of the calibration curve was $y=0.145 x+0.159\left(R^{2}=0.995\right)$, in the investigated concentration range of the target analyte between $1.5-80 \mathrm{ng} \mathrm{ml}{ }^{-1}$. The precision expressed as the relative standard deviation was in the range between 2 and $6 \%$. This data indicates a good reproducibility of the method.

As for the both described methods, the BM- and the FIA-TLS ones, the results are consistent with our earlier published paper [38], in which the LOD was achieved as $1.5 \mathrm{ng} \mathrm{ml}^{-1}$, and whereas the linearity of the calibration curves was obtained in the concentration range from 4.5 to $600 \mathrm{ng} \mathrm{ml}^{-1}$. The reason of a bit higher concentration range elaborated in the mentioned paper is the much shorter reaction time for nanoparticles generation $(\sim 3 \mathrm{~min})$, than in the case presented in this work $(\sim 15 \mathrm{~min})$.

The outlines of validation for the three plasmon generation based methods used in this study for the direct measurements of the colloidal silver or AgNPs are assumed in the Table 1. It is evident that the TLS methods showed nearly 60 -times lower LOD and LOQ values compared to the spectrophotometric one, which stem from the high sensitivity of TLS measurement techniques originating in the direct dependence of TLS signal on the excitation power of the applied laser and photothermal properties of the sample (for details see Introduction, Eqs. 1 and 2). The photo-thermal processes, which govern the generation of the thermal lens, should also explain the relatively narrow linearity range of the TLS methods, which mainly can be affected by eventual shift in the absorption maximum of the surface plasmon resonance band of AgNPs with their changes in concentration which resulting in the significant particulus size differences in the concentration range at $100 \mathrm{ng} \mathrm{mL}^{-1}$ and above. This shift effect has much lower consequences in the case of spectrophotometry since the analytical working wavelength of measurements is at the absorption maximum, while in case of TLS measurement techniques the pump laser working frequency is on the shoulder of the absorption band. The presented results confirm the sufficiently low LOQs for all three techniques, which can serve for determination of total or ionic silver in selected product with specified colloidal silver concentrations in the range of some ten $\mu \mathrm{g} \mathrm{ml}$ 1. Quantitation and speciation of silver (AgNPs, and/or $\mathrm{Ag}^{+}$converted chemically into the AgNPs) in the concentration range below $0.1 \mu \mathrm{g}$ $\mathrm{ml}^{-1}$ is however possible only with TLS techniques.

Inductively coupled plasma optical emission spectrometry: In ICP-OES technique the investigated target analytes is introduced into

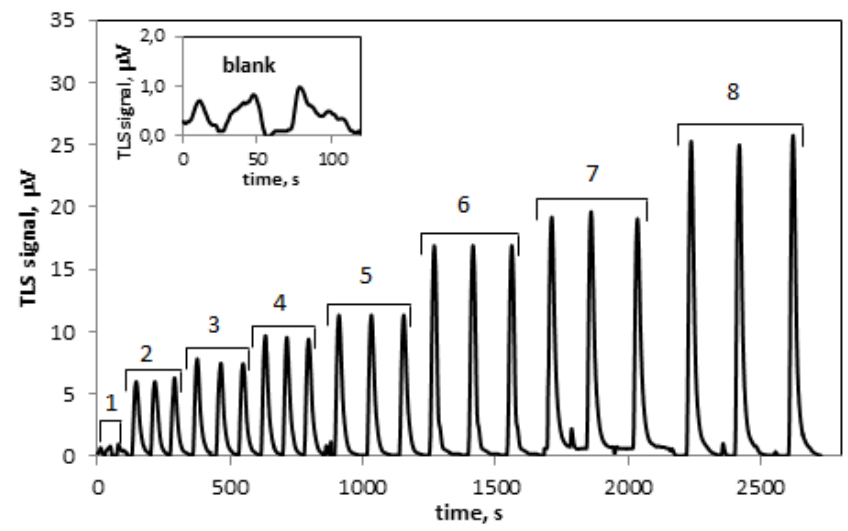

Figure 7: FIA signals for TLS detection of colloid silver corresponding to: 1 blank, $2-20 \mathrm{ng} \mathrm{ml}^{-1}, 3-40 \mathrm{ng} \mathrm{ml}^{-1}, 4-60 \mathrm{ng} \mathrm{ml}^{-1}, 5-80 \mathrm{ng} \mathrm{ml}^{-1}, 6-100 \mathrm{ng}$ $\mathrm{ml}^{-1}, 7-120 \mathrm{ng} \mathrm{ml}^{-1}$ and $8-160 \mathrm{ng} \mathrm{ml}^{-1}$. 
the plasma state by desolvating and ionising, and the analytical signal was generated by exciting of the specious of interest, i.e. ionic silver. The concentration of the ionic silver was determined on the basis of its emission line at working wavelenght $328 \mathrm{~nm}$, and quantified by their intensity. The LOD and LOQ for ionic silver determination was 10 and $30 \mathrm{ng} \mathrm{ml}^{-1}$, respectively. The linear range of the method was characterised by eqaution $y=231.6 \mathrm{x}+1.6\left(R^{2}=0.999\right)$ in the concentration range from $30 \mathrm{ng} \mathrm{ml}^{-1}$ to $500 \mathrm{ng} \mathrm{ml}^{-1}$, while the RSD of the method was between 3 and $6 \%$.

\section{Real samples analysis}

Several liquid samples containing colloid silver were analyzed, including nasal spray and drops, wounds' disinfection water, and liquid for internal intakes, directly by BM-TLS, FIA-TLS and spectrophotometry, and after the determination of initially present amount of colloidal silver and additional chemical conversion of the also present ionic silver (which was present in all samples) into the AgNPs, which sum is known as total silver, was measured again by same measurement techniques. For the comparison of total silver content in the investigated samples, after the appropriate sample treatment in acidic media when the all species of silver were converted into its ionic form the target analyte was measured by ICP-OES.

The applicability of the elaborated methods was tested by determining the concentration of colloidal silver in five samples of selected personal care products specified by their producers to contain colloidal silver in concentrations ranging from 5 to $30 \mu \mathrm{gL}^{-1}$. This was done by measuring the samples ' without reduction with borohydride. The obtained signals in the case of all three measurement techniques were evaluated from the appropriate calibration curves, described above, and the outlines are elaborated in the Table 2. After the direct TLS measurements the presence of colloidal silver was additionally confirmed by adding a drop (cc. $20 \mu \mathrm{l}$ ) of $0.1 \mathrm{M} \mathrm{HNO}_{3}$ solution to 10 $\mathrm{mL}$ of real sample to dissolve the initially present and measured AgNPs. After that sample treatment the TLS signal cannot be reproduced, what indicates the dissolution of initially present colloidal silver. After appropriate $\mathrm{pH}$ adjustment with $5 \mathrm{mM}$ phosphate buffer at $\mathrm{pH} 12.5$ and adding $1 \mathrm{ml}$ of $0.6 \mathrm{mM} \mathrm{NaBH}_{4}$ at $\mathrm{pH} 12.5$ to the final solution, the colloidal silver was formed again under controlled conditions, what was reflected in the value of measured TLS signal in accordance with earlier described similar protocol [38].

From the results in Table 2 it can be noticed, that the examined samples contained much less colloidal silver than it is stated by producers.

Therefore three samples were paralelly analyzed by optimized ICPOES method for additional control/confirmation of the validity of the results.

The results of ICP-OES measurements are 25-400 times higher after the acidic digestion of the samples. This however, does not indicate the disagreement with results of TLS and spectrophotometry, but rather suggests that most of the silver is in ionic form, because by ICP-OES only the ionic form of the target analyte can be determined which is in the present situation the total ionic silver concentration having in mind the sample preparation procedure and the nature of the chemically generated type of specie. On the other hand the both TLS techniques and UV-VIS spectrophotometry are not convenient for direct determination of ionic silver, as it was underlined these measurement techniques in combination with the optimized methods are suitable only for the determination of AgNPs.
In the further experimental steps the personal care products were treated by borohydride, which lead to the chemical conversion of ionic silver from the samples into the AgNPs, which means that additionally to the initially present AgNPs a portion of the AgNPs was generated forming on such way the total colloidal silver concentration. TLS and spectrophotometric measurements were performed in accordance with earlier procedure which apply the evaluation of the measured parameters by applying the calibration curves in the case of all used measurement techniques. The results are presented in the Table 3 and show remarkable higher AgNPs concentrations determined by TLS and spectrophotometry compared to results reported in Table 2. These values are in good agreement (at 99\% confidence level) with the experiment outlines obtained by ICP-OES and coincide well with the specifications of producers for the content of colloidal silver in their products.

Furthermore, a good agreement of the results was obtained for colloidal silver as well as for total silver measured in the form of AgNPs by both TLS and spectrophotometric methods for all real samples, since the statistical analysis of these results reveals, that the data obtained by all three measurement techniques and protocols are in agreementat at the confidence level (CL) of $99 \%$.

In details in case of sample 1 the CL includes values from 50 to 58 $\mathrm{ng} \mathrm{ml}{ }^{-1}$ and 10 to $26 \mu \mathrm{g} \mathrm{ml}^{-1}$ for the concentration of initial colloidal and total silver measured as total colloidal silver, respectively. For sample 2, $\mathrm{CL}$ includes the values between 94 and $134 \mathrm{ng} \mathrm{ml}^{-1}$ for AgNPs, whereas for the total amount of silver between 13 and $35 \mu \mathrm{g} \mathrm{ml}^{-1}$. The received values of CLs for sample 3 are 708-846 $\mathrm{ng} \mathrm{ml}^{-1}$ for the concentration of colloidal silver and $12-22 \mu \mathrm{g} \mathrm{ml}^{-1}$ for the total amount of it. CLs for sample 4 contains the values between 98 and $137 \mathrm{ng} \mathrm{ml}^{-1}$ in case of colloidal silver and between 16 and $24 \mathrm{\mu g} \mathrm{ml}^{-1}$ for the concentration of total silver. Sample 5 has got the CLs of values $98-137 \mathrm{ng} \mathrm{ml}^{-1}$ and 16-32 $\mu \mathrm{g} \mathrm{ml}{ }^{-1}$ for the concentration of colloidal and total silver, respectively.

\begin{tabular}{|c|c|c|c|c|}
\hline Method & $\begin{array}{l}\text { Linearity range } \\
{[\text { [ng ml-1] }}\end{array}$ & $\mathbf{R}^{2}$ & LOD $\left[\mathrm{ng} \mathrm{ml} \mathrm{m}^{-1}\right]$ & LOQ [ng ml-1] \\
\hline BM-TLS & $0.30-80$ & 0.996 & 0.090 & 0.30 \\
\hline FIA-TLS & $1.5-80$ & 0.995 & 0.45 & 1.5 \\
\hline UV-VIS & $90-1200$ & 0.996 & 27 & 90 \\
\hline
\end{tabular}

Table 1: The linearity ranges, correlation coefficients and values of LODs and LOQs achieved for the spectrometric methods used in this study for the determination of AgNPs.

\begin{tabular}{|l|c|c|c|}
\hline & BM-TLS $\left[\mu \mathrm{m} \mathrm{ml}^{-1}\right.$ ] & FIA-TLS $\left[\mu \mathrm{m} \mathrm{ml}^{-1}\right.$ ] & $\begin{array}{c}\text { Spectrophotometry } \\
{\left[\mu \mathrm{g} \mathrm{ml}^{-1} \text { ] }\right.}\end{array}$ \\
\hline Sample 1 & $0.054 \pm 0.001$ & $0.053 \pm 0.003$ & not measurable- \\
\hline Sample 2 & $0.114 \pm 0.005$ & $0.132 \pm 0.006$ & $0.108 \pm 0.002$ \\
\hline Sample 3 & $0.780 \pm 0.017$ & $0.772 \pm 0.006$ & $0.711 \pm 0.003$ \\
\hline Sample 4 & $0.117 \pm 0.005$ & $0.096 \pm 0.004$ & $0.106 \pm 0.004$ \\
\hline Sample 5 & $0.270 \pm 0.010$ & $0.252 \pm 0.006$ & $0.284 \pm 0.002$ \\
\hline
\end{tabular}

Table 2: The concentration of colloidal silver and its standard deviation in the examined samples determined by BM-TLS, FIA-TLS and spectrophotometry.

\begin{tabular}{|l|c|c|c|c|}
\hline & $\begin{array}{c}\text { BM-TLS } \\
{\left[\mu \mathrm{ml}^{-1}\right]}\end{array}$ & $\begin{array}{c}\text { FIA-TLS } \\
{\left[\mu \mathrm{m} \mathrm{ml}^{-1}\right]}\end{array}$ & $\begin{array}{c}\text { Spectrophotometry } \\
{\left[\mu \mathrm{g} \mathrm{m}^{-1}\right]}\end{array}$ & $\begin{array}{c}\text { ICP-OES } \\
{\left[\mu \mathrm{ml}^{-1}\right]}\end{array}$ \\
\hline Sample 1 & $18 \pm 1$ & $25 \pm 2$ & $26 \pm 2$ & $23 \pm 1$ \\
\hline Sample 2 & $24 \pm 1$ & $33 \pm 2$ & $35 \pm 2$ & $28 \pm 1$ \\
\hline Sample 3 & $17 \pm 2$ & $20 \pm 1$ & $22 \pm 1$ & $18 \pm 1$ \\
\hline Sample 4 & $20 \pm 1$ & $23 \pm 2$ & $20 \pm 1$ & not measured. \\
\hline
\end{tabular}

Table 3: The concentration of total silver in the examined samples determined by BM-TLS, FIA-TLS, spectrophotometry and ICP-OES. 
Citation: Korte D, Grahovac A, Jerkič A, Vajdle O, Anojčić J, et al. (2018) Speciation and Determination of lonic and Trace-Level Colloidal Silver in Selected Personal Care Products by Thermal Lens Spectrometry. Pharm Anal Acta 9: 573. doi: 10.4172/2153-2435.1000573

Page 8 of 10

These findings confirms that the TLS techniques, both in FIA and batch working mode, are reliable and highly sensitive analytical tools for determination of colloidal silver either from the AgNPs originally present into the personal care product samples or from the $\mathrm{Ag}^{+}$species converted by chemical reduction into the measurable AgNPs from of all investigated products.

\section{Concentration of silver deposited on containers}

The adsorption of silver species including the colloidal silver one on the walls of the containers, in which the products were sold, was investigated in details. To check for the content of the total silver deposited on the walls of containers, they were washed with $\mathrm{HNO}_{3}$ solution to dissolve any colloidal silver deposited or adsorbed on the container. The $\mathrm{pH}$ of the leachates with ionic silver was adjusted by phosphate buffer and after adding $\mathrm{NaBH}_{4}$ the concentrations of AgNPs in leachate solutions were determined by BM-TLS method and in some cases parallelly by FIA-TLS as well. Two of such samples measured by FIA-TLS at the same run in triplicate injection of the samples are illustrated at the (Figure 8). The outlines of the experiments dealing with all five samples are elaborated in details in the Table 4. Considering the dilution during the process of dissolution and subsequent $\mathrm{pH}$ adjustment and reduction process, the total amounts of silver deposited on the walls of the containers were calculated by appropriate multiplying the determined concentrations of AgNPs in leachate solutions. Note, that in case of sample 4 and 5 it was determined by TLS in both BM and FIA (Figure 8), whereas in case of samples 1-3 only by BM-TLS. The received values of AgNPs concentrations were compared with the values of AgNPs in the samples declared by their producers.

As can be calculated from the results in Table 4 in combination with by producers declared concentrations of the colloidal silver in the samples, the amount of silver adsorbed on the walls is only $0.1 \%$ of total amounts of silver in containers or less. The nature of the species of $\mathrm{Ag}$ on the container walls cannot be discriminated since washing with $\mathrm{HNO}_{3}$, washes any adsorbed $\mathrm{Ag}^{+}$, but it also dissolves colloidal Ag yielding producing silver ions. However, even if all of the silver deposited on the container walls would be colloidal this cannot account for such low concentrations of colloidal silver as determined in the examined samples.

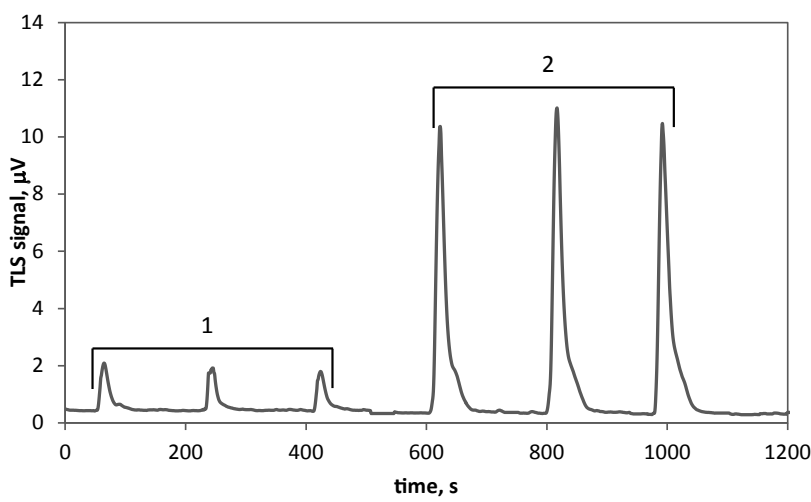

Figure 8: TLS signals in FIA configuration of the experimental setup for silver species deposited on the bottle in which the colloidal solution was stored after washing it with nitric acid solution and $\mathrm{pH}$ adjustment it with phosphate buffer and addition of reductant (1-sample 4, 2-sample 5).

\section{Colorimetric characterization}

During the experimental work it was recognized, that the investigated samples (except sample 3) were colorless, while the standard solutions with concentrations comparable to specified contents of colloidal Ag were all yellowish after reduction with borohydride. The coloration was noticed for all solutions with silver concentration of about $1 \mu \mathrm{g} \mathrm{ml}^{-1}$ and higher. This suggests that the colorimetric evaluation of the samples can be used as a preliminary step in assessing the concentration and the form of silver present in the personal care products. A colorless sample is a clear indication of colloidal silver concentrations between 0.050 and $0.78 \mu \mathrm{g} \mathrm{ml}^{-1}$. On the other hand, a yellowish color of the sample does not automatically mean the presence of AgNPs, since other constituents of the sample(s) might contribute to the colour. To confirm the presence of AgNPs, the samples can be treated with $\mathrm{HNO}_{3}$ solution $(0.1 \mathrm{M})$, which resulted in discoloration and appearance of the colour again after $\mathrm{pH}$ adjustment and reduction with borohydride. This procedure is utilized in TLS determination of colloidal silver to confirm the origin of TLS signal from colloidal Ag $[16,38]$. Similarly, a simple addition of borohydride to investigated sample should confirm any presence of silver ions at concentrations between 17 and $35 \mu \mathrm{g} \mathrm{ml}^{-1}$. In our case adding borohydride to the examined samples to reduce ionic silver potentially present in the samples resulted in intensive yellowish coloring of the solutions similar to the colour of standards (Figure 9). This additionally confirms, that most of the silver present in examined samples is not colloidal but is rather in the ionic form.

\begin{tabular}{|c|c|c|c|}
\hline & \multicolumn{3}{|c|}{$\begin{array}{c}\text { Determined concentration of total silver in leachate [ng } \\
\text { ml-1 }^{-1}\end{array}$} \\
\hline Sample 1 & \multicolumn{3}{|c|}{$155 \pm 1$} \\
\hline Sample 2 & \multicolumn{3}{|c|}{$161 \pm 1$} \\
\hline Sample 3 & \multicolumn{3}{|c|}{$317 \pm 2$} \\
\hline Sample 4 & $13 \pm 1(\mathrm{BM})$ & \multicolumn{2}{|c|}{$15 \pm 1(\mathrm{FIA})$} \\
\hline Sample 5 & $11 \pm 1(\mathrm{BM})$ & $30 \pm 2$ & $\begin{array}{c}\text { not } \\
\text { measured }\end{array}$ \\
\hline Sample 5 & $31 \pm 2$ & $26 \pm 1$ & 30 (FIA) \\
\hline
\end{tabular}

Table 4: The concentrations of total silver in leachates obtained from the walls of the sample containers.

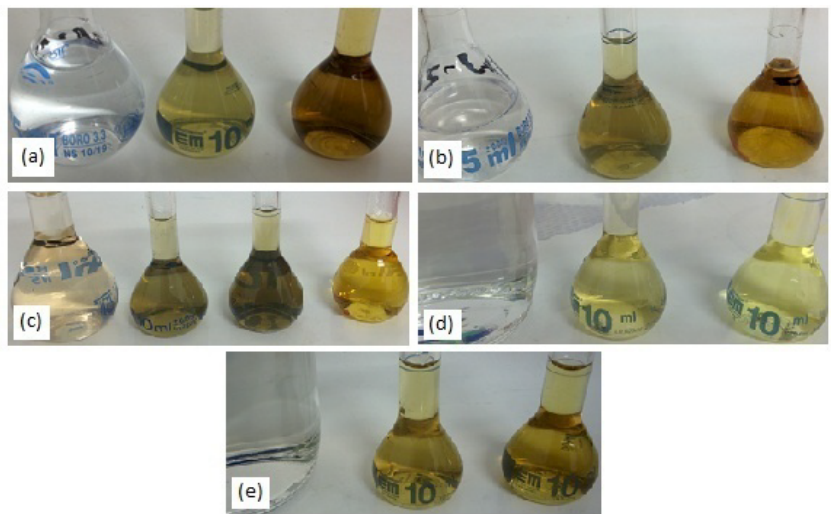

Figure 9: Examined samples and relevant standard solutions, from the left to the right: (a) sample $1,15 \mu \mathrm{g} \mathrm{ml}^{-1}$ standard solutions, sample 1 with $1 \mathrm{~mL}$ of borohydride; (b) sample 2, $20 \mu \mathrm{g} \mathrm{ml}^{-1}$ standard solution, sample 2 with $1 \mathrm{~mL}$ of borohydride; (c) sample $3,25 \mu \mathrm{g} \mathrm{ml}^{-1}$ standard solution, $30 \mu \mathrm{g} \mathrm{ml}^{-1}$ standard solution, sample 3 with $1 \mathrm{ml}$ of borohydride; (d) sample $4,5 \mu \mathrm{g} \mathrm{ml}^{-1}$ standard solution, sample 4 with $1 \mathrm{ml}$ of borohydride; (e) sample $5,15 \mathrm{\mu g} \mathrm{ml}^{-1}$ standard solution, sample 5 with $1 \mathrm{ml}$ of borohydride. 
Citation: Korte D, Grahovac A, Jerkič A, Vajdle O, Anojčić J, et al. (2018) Speciation and Determination of lonic and Trace-Level Colloidal Silver in Selected Personal Care Products by Thermal Lens Spectrometry. Pharm Anal Acta 9: 573. doi: 10.4172/2153-2435.1000573

\section{Conclusion}

In the study the thermal lens spectroscopy was successfully applied for determining the colloidal and total amount of silver in the form of colloidal silver in 5 personal care product samples from different producers. It was found, that the examined samples contain larger amounts of ionic silver, whereas it colloidal specie is at the level of less than $1 \mu \mathrm{g} \mathrm{mL} L^{-1}$, whereas the amount of ionic silver was between 18 and $35 \mu \mathrm{g} \mathrm{ml}{ }^{-1}$, what indicates that the amount of silver declared by the producers refer mainly to its total amount. It was also demonstrated, that TLS either in the batch working mode or in flow injection analysis configuration is a suitable technique for direct application to analytical determination of silver species in liquid samples. The proposed methods have excellent characteristics such as very low detection limit $(0.090$ and $0.45 \mathrm{ng} \mathrm{ml}^{-1}$ for BM and FIA mode, respectively) and present good accuracy, sensitivity and precision.

The presented results also indicate a clear need for quality control of personal care products, specified to contain colloidal silver, since the analysis of randomly selected five products among those available on the market, has shown that they contain concentrations of colloidal silver is lower (below $1 \mu \mathrm{g} \mathrm{ml}^{-1}$ in all cases) than those declared by the producers.

\section{Acknowledgement}

The authors would like to thank to CEEPUSIII CZ 2012 for support and thus enabling to perform the joint research, as well as to the Slovenian Research Agency for funding this work through research grants P1-0034: "Analytics and chemical characterization of materials and processes".

\section{References}

1. Stoimenov PK, Klinger RL, Marchin GL, Klabunde KJ (2002) Metal oxide nanoparticles as bactericidal agents. Langmuir 18: 6679-6686.

2. Pal S, Tak YK, Song JM (2007) Does the antibacterial activity of silver nanoparticles depend on the shape of the nanoparticle? A study of the gramnegative bacterium Escherichia coli. Appl Environ Microbiol 73: 1712-1720.

3. Drake PL, Hazelwood KJ (2005) Exposure-related health effects of silver and silver compounds: a review. Ann Occup Hyg 49: 575-585.

4. Franci G, Falanga A, Galdiero S, Palomba L, Rai M, et al. (2015) Silver nanoparticles as potential antibacterial agents. Molecules 20: 8856-8874.

5. Arora S, Jain J, Rajwade JM, Paknikar KM (2009) Interactions of silver nanoparticles with primary mouse fibroblasts and liver cells. Toxicol Appl Pharmacol 236: 310-318.

6. AshaRani PV, Low KMG, Hande MP, Valiyaveettil S (2008) Cytotoxicity and genotoxicity of silver nanoparticles in human cells. ACS Nano 3: 279-290.

7. Foldbjerg R, Olesen P, Hougaard M, Dang DA, Hoffmann HJ, et al. (2009) PVPcoated silver nanoparticles and silver ions induce reactive oxygen species, apoptosis and necrosis in THP-1 monocytes. Toxicol Lett 190: 156-162.

8. Kasraei S, Sami L, Hendi S, AliKhani MY, Rezaei-Soufi L, et al. (2014) Antibacterial properties of composite resins incorporating silver and zinc oxide nanoparticles on Streptococcus mutans and Lactobacillus. Restor Dent Endod 39: 109-114.

9. Corrêa JM, Mori M, Sanches HL, Cruz ADD, Poiate E, et al. (2015) Silver nanoparticles in dental biomaterials. Int J Biomater

10. Seymour C (2006) Audit of catheter-associated UTI using silver alloy-coated Foley catheters. Br J Nurs 15: 598-603.

11. Parker D, Callan L, Harwood J, Thompson DL, Wilde M, et al. (2009) Nursing interventions to reduce the risk of catheter-associated urinary tract infection: Part 1: Catheter Selection. J Wound Ostomy Continence Nurs 36: 23-34.

12. Ge L, Li Q, Wang M, Ouyang J, Li X, et al. (2014) Nanosilver particles in medica applications: synthesis, performance, and toxicity. Int J Nanomedicine 9: 2399.

13. Knetsch ML, Koole LH (2011) New strategies in the development of antimicrobial coatings: the example of increasing usage of silver and silver nanoparticles. Polymers 3: 340-366.
14. Silver S, Phung LT, Silver G (2006) Silver as biocides in burn and wound dressings and bacterial resistance to silver compounds. J Ind Microbio Biotechnol 33: 627-634.

15. Carter MJ, Tingley-Kelley K, Warriner RA (2010) Silver treatments and silverimpregnated dressings for the healing of leg wounds and ulcers: a systematic review and meta-analysis. J Ame Acad Dermatol 63: 668-679.

16. Tran CD, Prosenc F, Franko M, Benzi G (2016) One-pot synthesis of biocompatible silver nanoparticle composites from cellulose and keratin: characterization and antimicrobial activity. ACS Appl Mater Interfaces 8: 34791-34801.

17. http://www.nanotechproject.org/cpi/browse/nanomaterials/silver-nanoparticle

18. Lansdown AB (2010) A pharmacological and toxicological profile of silver as an antimicrobial agent in medical devices. Adv Pharmacol Sci.

19. Wilkinson LJ, White RJ, Chipman JK (2011) Silver and nanoparticles of silver in wound dressings: a review of efficacy and safety. J Wound Care 20: 543-549.

20. (1999) Department of health and human services, food and drug administration, Federal Register 64: 44653-44658.

21. Blazheva T, Delijska-Krushevska A (1990) AAS method for the determination of silver in ores and ore dressing products. Fresenius J Anal Chem 338: 294-296.

22. Valverde F, Costas M, Pena F, Lavilla I, Bendicho C (2008) Determination of total silver and silver species in coastal seawater by inductively-coupled plasma mass spectrometry after batch sorption experiments with Chelex-100 resin. Chem Spec Bioavailab 20: 217-226.

23. Radulescu MC, Chira A, Radulescu M, Bucur B, Bucur MP, et al. (2010) Determination of silver (i) by differential pulse voltammetry using a glassy carbon electrode modified with synthesized N-(2-Aminoethyl)-4, 4'-Bipyridine. Sensors 10: 11340-11351.

24. Rubinova N, Chumbimuni-Torres K, Bakker E (2007) Solid-contact potentiometric polymer membrane microelectrodes for the detection of silver ions at the femtomole level. Sens Actuators B Chem 121: 135-141.

25. Szigeti Z, Malon A, Vigassy T, Csokai V, Grün A, et al. (2006) Nove potentiometric and optical silver ion-selective sensors with subnanomolar detection limits. Analytica chimica acta 572: 1-10.

26. Wygladacz K, Radu A, Xu C, Qin Y, Bakker E (2005) Fiber-optic microsensor array based on fluorescent bulk optode microspheres for the trace analysis of silver ions. Analytical chemistry 77: 4706-4712.

27. Hu Q, Guangyu Y, Huang Z, Yin J (2002) Spectrophotometric determination of silver with 2-(2-quinolylazo)-5-diethylaminoaniline. Talanta 58: 467-473.

28. Ensafi AA, Zarei K (1997) Flow injection determination of silver with spectrophotometric detection. Fresenius J Anal Chem 358: 475-479.

29. Itabashi $\mathrm{H}$, Takahata M, Kawamoto $\mathrm{H}$, Akaiwa $\mathrm{H}$ (1998) Catalytic determination of silver (I) by extractive flow injection analysis. Talanta 45: 549-555.

30. Cascio C, Geiss O, Franchini F, Ojea-Jimenez I, Rossi F, et al. (2015) Detection, quantification and derivation of number size distribution of silver nanoparticles in antimicrobial consumer products. J Anal At Spectrom 30: 1255-1265.

31. Loeschner K Navratilova J, Grombe R, Linsinger TP, Købler C et al. (2015) In-house validation of a method for determination of silver nanoparticles in chicken meat based on asymmetric flow field-flow fractionation and inductively coupled plasma mass spectrometric detection. Food chem 181: 78-84.

32. Dobre N, Golgovici F, Anicai L, Buda M (2014) Cyclic voltammetry of silver nanoparticles on platinum, gold and glassy carbon electrodes. Rev ChimBucharest 65: 578-581.

33. Zhou YG, Rees NV, Compton RG (2011) The electrochemical detection and characterization of silver nanoparticles in aqueous solution. Angew Chem Int Edit 50: 4219-4221.

34. Bartlett TR, Sokolov SV, Compton RG (2015) Electrochemical nanoparticle sizing via nano-impacts: how large a nanoparticle can be measured?. Chemistry Open 4: 600-605.

35. Novotný L, Petrankova R (2016) Potentiometric determination of silver nanoparticles using silver amalgam electrodes. Anal Lett 49: 161-168.

36. Hill AA, Lipert RJ, Porter MD (2010) Determination of colloidal and dissolved silver in water samples using colorimetric solid-phase extraction. Talanta 80 1606-1610. 
Citation: Korte D, Grahovac A, Jerkič A, Vajdle O, Anojčić J, et al. (2018) Speciation and Determination of lonic and Trace-Level Colloidal Silver in Selected Personal Care Products by Thermal Lens Spectrometry. Pharm Anal Acta 9: 573. doi: 10.4172/2153-2435.1000573

Page 10 of 10

37. Bruzzoniti MC, Kobylinska DK, Franko M, Sarzanini C (2010) Flow injection method for the determination of silver concentration in drinking water for spacecrafts. Anal Chim Acta 665: 69-73.

38. Korte D, Bruzzoniti MC, Sarzanini C, Franko M (2011) Thermal lens spectrometric determination of colloidal and ionic silver in water. Int $J$ Thermophys 32: 818-827.

39. Mulfinger L, Solomon SD, Bahadory M, Jeyarajasingam AV, Rutkowsky SA, et al. (2007) Synthesis and study of silver nanoparticles. J Chem Educ 84: 322.

40. Leach RA, Carter CA, Harris JM (1984) Least-squares polynomial filters for initial point and slope estimation. Anal Chem 56: 2304-2307.
41. Liu M, Franko M (2016) Thermal lens spectrometry: still a technique on the horizon?. Int J Thermophys 37: 67.

42. Li WR, Xie XB, Shi QS, Zeng HY, You-Sheng OY, et al. (2010) Antibacteria activity and mechanism of silver nanoparticles on Escherichia coli. Appl Microbiol Biotechnol 85: 1115-1122.

43. Simone G, Robouch P (2014) EURL-FA guide: protocol for verification studies of single laboratory/in-house validated methods.

44. Long GL, Winefordner JD (1983) Limit of detection. A closer look at the IUPAC definition. Anal Chem 55: 712A-724A.

45. Devore J, Farnum N (2004) Applied statistics for engineers and scientists. Thomson Learning, New York, USA. 